\title{
“MORTE DE UMA BALEIA", DE CLARICE LISPECTOR: POR UMA ESCRITURA BIOPOLÍTICA
}

Fabrício Lemos da Costa* Silvio Augusto de Oliveira Holanda**

RESUMO: O presente estudo tem como objetivo refletir criticamente acerca da crônica "Morte de uma baleia", de Clarice Lispector (1920-1977), publicada pela primeira vez no Jornal do Brasil, em 17 de agosto de 1968. Para isto, desenvolveremos uma análise pela perspectiva da biopolítica, a qual nos auxilia a pensar, no plano artístico, a animalidade como questão que instaura uma discussão política, sobretudo em torno da relação entre a vida, a morte e o poder. Neste artigo, destacamos os estudos de Giorgi (2016), Nascimento (2012, 2013) e Maciel (2011). Ao lado destes últimos, enfatizamos também as reflexões sobre o animal e o devir em Deleuze e Guattari (1980).

PALAVRAS-CHAVE: Clarice Lispector, "Morte de uma baleia", Biopolítica.

Não quero acreditar que alguém desrespeite tanto a vida e a morte, nossa criação bumana, e que coma vorazmente, só por ser uma iguaria, aquilo que ainda agoniza.

"Morte de uma baleia", Clarice Lispector'

A crônica "Morte de uma baleia", de Clarice Lispector, foi publicada pela primeira vez no Jornal do Brasil, em 17 de agosto de 1968. Trata-se de uma das várias contribuições de nossa ilustre escritora neste veículo de comunicação. Veiculadas, geralmente, aos sábados, as crônicas de Lispector ocupavam no periódico, um momento privilegiado à reflexão crítica dos leitores do jornal, daí saírem nos números dos finais de semana, momento em que, em tese, o leitor teria mais tempo livre para ler textos que demandassem uma maior

\footnotetext{
* Mestrando em Letras pela Universidade Federal do Pará (Ufpa)

** Doutor em Letras (Teoria Literária e Literatura Comparada) pela Universidade de São Paulo (Usp). Professor Associado IV da Universidade Federal do Pará (Ufpa).

${ }^{1}$ LISPECTOR, 1968, p. 2.

${ }^{2}$ Disponibilizamo-la em anexo.
} 
concentração e dedicação. Assim, o gênero crônica, como sabemos, com questões ligadas ao cotidiano ${ }^{3}$, apresenta na ficção clariceana uma interessante capacidade reflexiva pelo caminho da interiorização.

Em "Morte de uma baleia", por exemplo, vemos despontar um fato, aparentemente, banal, desses que seriam manchetes de único dia num jornal, mas que se desenvolve como escritura ${ }^{4}$ de evidente qualidade no que tange ao teor "pensante", estimulado pela presença do animal e na elevada introjeção de um sujeito da enunciação. Como evidencia Yudith Rosenbaum (2019), "a crônica, tão familiarmente considerada como o gênero da contingência leve e fortuita, adquire na obra de Lispector uma densidade inusitada" (ROSENBAUM, 2019, p. 25).

No texto "Morte de uma baleia", uma notícia se transforma em matéria literária. Conta-se a história de duas baleias encalhadas nas praias do Leme e do Leblon. Presas durante horas, sofrem, agonizam, e, ainda vivas, suas carnes são vendidas aos curiosos que se aproximam para presenciar aquele martírio dos bichos, os quais são negociados, por valor irrisório, com os transeuntes. Deste acontecimento, em que um "Eu" se nega a ir vêlas, in loco, vemos crescer, no plano estético, um significante convite à reflexão crítica, sobretudo no que tange aos viventes e ao poder que se exerce sobre eles. Antes de iniciarmos a análise da crônica, propriamente dita, gostaríamos de problematizar algumas questões fundamentais para a nossa interpretação. A primeira diz respeito à literatura de Clarice Lispector como da "ordem" da ficção pensante. Para isto, recorremos ao crítico Evando Nascimento (2012), que sinaliza em seus estudos este aspecto. Para ele:

Uma literatura pensante como a de Clarice é a que possibilita pensar o impensável; e só pode haver pensamento ali onde se dá o advento da alteridade enquanto tal, o outro como Outro ou Outra, em sua

\footnotetext{
${ }^{3}$ Cf. MOISÉS, 2013, p. 113: "Modalidade literária sujeita ao transitório e à leveza do jornalismo, a crônica sobrevive quando logra desentranhar o perene da sucessão anódina de acontecimentos diários, e graças aos recursos de linguagem do prosador. Sucedendo tais circunstâncias, afigura-se que a inspiração do escritor apenas se materializou em crônica por uma feliz coincidência entre o fato passageiro e as matrizes da sua faculdade criadora."

${ }^{4}$ Entendemos "escritura", neste trabalho, como texto que se inscreve em "pensamento", perfazendo-se como oportunidade, assim, de instaurar uma possível mudança no leitor, na maneira como este pensava anteriormente à leitura. Trata-se, neste caso, do intento de uma reflexão crítica que envolve a transformação dos leitores.
} 
radical diferença. Por exemplo, uma animalidade irredutível ao antropocentrismo; ou uma humanidade totalmente afim da questão animal e do vivo em geral, e não sua inimiga predadora. Pensar o mundo é, pois, possibilitar o próprio pensamento, no limite da impossibilidade e de forma aporética. (NASCIMENTO, 2012, p. 24)

Em suma, pela particularidade pensante, a literatura de Clarice Lispector se emenda como plano reflexivo sobre o mundo. Neste bojo, é a relação humano/animal que ganha um enorme destaque, pensando-a como alteridade radical. Assim, o caráter do "pensamento", como assinala Nascimento em relação aos escritos ficcionais da autora, poder-seia alargar-se às crônicas, vendo-as, pois, como parte de uma produção, imersa ao cotidiano, e que carrega uma potência em questões envolvendo o animal com sua dor e o humano em suas decisões. Perfazem-se, então, como matéria destas escrituras. Dessa maneira, entendemos a crônica "Morte de uma baleia", como exemplar desta característica, a qual Nascimento chama de pensante. Com ela, vê-se, artisticamente, o lugar do animal e do poder que o humano exerce na vida dos viventes. Ao longo de nossa reflexão, ainda vamos problematizar esta questão da literatura pensante, tendo-se como base o corpus deste trabalho.

Outro viés que se faz necessário em nossa leitura de "Morte de uma baleia", colocase nas discussões que envolvem certas literaturas contemporâneas como "espaço" de reflexão sobre o animal, considerando-o como "signo político". Para esta abordagem, buscamos os argumentos de Gabriel Giorgi (2016) em Formas Comuns: animalidade, literatura, biopolítica. Para ele, na esteira do pensamento de Michel Foucault, "a cultura inscreveu a vida animal e a ambivalência entre humano e animal como via para pensar os modos como nossas sociedades traçam distinções entre vidas por proteger e vidas por abandonar, o que é o eixo fundamental da biopolítica" (GIORGI, 2016, p. 12). Ao instaurar o problema sobre as vidas, que ele sublinha como "proteção" e "abandono", revela-se, então, um panorama complexo que se encontra na base do poder sobre certas vidas. Assim, elegemos em nossa interpretação estas duas questões: a literatura clariceana como estimuladora do pensamento e a reflexão pela via biopolítica, que acreditamos estar imbuído no texto "Morte de uma baleia". 
Deve-se considerar, dessa maneira, a crônica em questão como parte de uma reflexão maior, instaurada, principalmente, na década de 1960 na literatura latino-americana, em que a produção ficcional de Clarice Lispector também é representante. Gabriel Giorgi, em "Introdução" ao seu livro, o qual já mencionamos, esclarece:

Certa insistência atravessa muitos percursos das culturas latino-americanas ao menos a década de 1960: a que faz do animal, e da vida animal, a instância de uma proximidade inquietante, de uma cercania e de uma intimidade que problematiza e desordena os modos como as culturas haviam dado forma ao humano por sua contraposição, sua distância e sua hierarquia com respeito do animal. (GIORGI, 2016, p. 7 , grifo nosso)

Neste destaque, o animal, como grifamos na citação de Giorgi, passa a ser abordado como oportunidade de inserir uma discussão ampla sobre o Outro. Este Outro, em síntese, coloca-se nestas literaturas como linha do pensamento pela alteridade. Nela, indaga-se os limites do homem e do animal, além disso, a obra se coloca como um espaço de aberturas de questões sobre "vidas por proteger, por cuidar, por 'futurizar"' (GIORGI, 2016, p. 12). Neste intento, é o político, por via do artístico, que assume um papel fundante nestas diversas narrativas, em maioria, latino-americanas. No fundo, como assinala Giorgi, o "animal começa a funcionar de modos cada vez mais explícitos como um signo político" (GIORGI, 2016, p. 10, grifo do autor). Explicado o problema que se coloca em nosso estudo, vejamos um trecho inicial da crônica "Morte de uma baleia":

Em minutos espalhara-se a notícia: uma baleia no Leme e outra no Leblon haviam surgido na arrebentação de onde tinham tentado sair sem no entanto poder voltar. Eram descomunais apesar de apenas filhotes. Todos foram ver. Eu não fui: corria o boato de que ela agonizava já há oito horas e que até atirar nela haviam atirado mas ela continuava agonizando e sem morrer. (LISPECTOR, 1968, p. 2)

Pelo excerto inicial, vê-se o lugar do animal neste texto, nascida como matéria delicada: "senti um horror diante do que contavam e que talvez não fossem estritamente os fatos reais" (LISPECTOR, 1968, p. 2). Todavia, fica claro, nesta passagem, a relação entre a morte da baleia e o poder humano exercido sobre ela: "até atirar nela haviam atirado mas 
ela continuava agonizando e sem morrer". Em síntese, a causa da agonia do animal tem início com seu encalhamento, entretanto, a ação do homem, seu poderio, instala na história, que, aliás, talvez, nem seja da maneira como contavam ${ }^{5}$, como se demonstra no texto, no plano da reflexão artística, uma questão ética e política (biopolítica), vista na perspectiva, neste caso, de um vivente "marginal".

Em suma, expande-se, aqui, o problema sobre vidas que são arrastadas, com facilidade e sem horror de muitos, para a morte, o abatimento e a agonia. Neste viés, vemos prefigurar o agravo de "vidas que se abandonam, que se reservam para a exploração, para a coisificação, ou diretamente para o abandono ou para a eliminação" (GIORGI, 2016, p. 13). De outro lado, o homem, mas nem todos, que devem ser cuidados, alimentados e protegidos, com o fim de mantê-los saudáveis e com direito ao futuro. Na crônica, é este paralelo a clave de um fundamento político que se coloca: "Se fosse um homem que estivesse agonizando na praia durante oito horas nós o santificaríamos, tanto precisamos de crer no que é impossível" (LISPECTOR, 1968, p. 2). Temos, aqui, a linha comparativa: de um lado, os animais, do outro, o homem, santificado mais ainda quando na presença da dor, caminhos que são do sublime.

No animal, ao contrário, reclama-se o direito de tê-lo cativo, decidindo-se entre a sua vida ou a sua morte. Neste sentido, em "Morte de uma baleia", crônica do final da década de 60, como pensa Giorgi (2016), “o animal se torna um umbral de exploração crítica e de interrogação estética” (GIORGI, 2016, p. 19). Assim, dessa indagação do animal como matéria ficcional que "arrasta" a reflexão crítica para as discussões ético-políticas, vemos emergir a possiblidade de deslocamentos em torno de um suposto lugar fixo do bicho, visto apenas como coisa ou objeto, para um outro, quem sabe, de uma possível aliança entre homem e animal, enfim, de uma alteridade.

Na narrativa, esta alteridade se alarga como internalização na vivência daquela que instala a discussão. Poder-se-ia falar, aqui, de um animal que ativa uma retórica de 
intensidade $^{6}$, ou seja, de um aprofundamento do interior de um Eu da enunciação. Para o caso de A Paixão Segundo G.H., Giorgi (2016), afirma ser a relação homem/animal da ordem do "multiplicado em suas dobras interiores- expansivo, poderia dizer-se, em sua própria interiorização" (GIORGI, 2016, p. 110). Dessa forma, aceitamos o argumento de Giorgi, no qual acreditamos ser acertado para pensarmos também o animal em "Morte de uma baleia". Texto breve, próprio das crônicas, publicadas em periódicos, geralmente, nas chamadas colunas literárias, carrega, no entanto, uma potência interessante no que tange à intimidade do sujeito. Como dissemos, conforme a proposta interpretativa de Giorgi, dáse, pelo animal, expandindo-se para o Eu, uma espécie de "assédio" do bios, como ressalta Giorgi (2016, p. 138). O Eu, assim, se recusa a ir vê-las, todavia, o animal já estava prefigurado como escritura. Vejamos:

Não, não fui vê-la: detesto a morte. Deus, o que nos prometeis em troca de morrer? Pois o céu e o inferno nós já os conhecemos - cada um de nós em segredo quase de sonho já viveu um pouco do próprio apocalipse. E a própria morte.

Fora das vezes em que quase morri para sempre, quantas vezes num silêncio humano - que é o mais grave de todos do reino animal quantas vezes num silêncio humano minha alma agonizando esperava por uma morte que não vinha. E como escárnio, por ser o contrário do martírio em que minha alma sangrava, era quando o corpo mais florescia. (LISPECTOR, 1968, p. 2)

No fragmento, poderíamos retirar todo um inventário de vocábulos típicos da ficção clariceana, como "morte", "Deus" e "silêncio". Tais palavras, como explicamos, anteriormente, justificam, ao lado do animal, uma produção que se intensifica no sujeito, marcada em uma vivência que se perfaz no "céu" e no "inferno" de cada um. Vê-se, neste

\footnotetext{
${ }^{6}$ Cf. LISPECTOR, 1968, p. 2: "Lembro-me agora de uma vez que ao olhar um pôr do sol interminável e escarlate também eu agonizei com ele lentamente e morri, e a noite veio para mim cobrindo-me de mistério, de insônia clarividente e, finalmente por cansaço, sucumbido num sono que completava a minha morte. E quando acordei, surpreendi-me docemente. Nos primeiros ínfimos instantes de acordada pensei: então quando se está morta se conserva a consciência? Até que o corpo habituado a mover-se automaticamente me fez fazer um gesto muito meu: o de passar a mão pelos cabelos. Então num susto percebi que meu corpo e minha alma tinham sobrevivido. Tudo isto - a certeza de estar morta e a descoberta de que eu estava viva- tudo isto não durou, creio, mais que dois ínfimos segundos ou menos ainda."
} 
sentido, que, da agonia do corpo daqueles animais encalhados nas praias, se elabora, no corpo do sujeito da enunciação, uma "alma" que também "sangrava", um 'martírio" íntimo que "florescia" no corpo daquela. Ao se recusar ir vê-las, não deixa de sentir horror, no fundo, uma dor que se estende do corpo do Outro para si, portanto, em estranhamento.

Neste ínterim, a relação Eu/animal em "Morte de uma baleia", configura aquilo que Evando Nascimento (2012, p. 27), em Clarice Lispector: uma literatura pensante, considera como "chamado" ou "vocação" ao selvagem, no qual se inscreve como experiência que se afirmaria "no estranhamento de si mesmo" (NASCIMENTO, 2012, p. 32). Dessa maneira, como literatura pensante, a crônica clariceana instiga, pelo animal, a questionarmos certos limites, zonas fronteiriças entre o homem e o bicho. Ainda segundo Nascimento:

O pensamento da relação homem-animal é o pensamento do limite, das zonas fronteiriças e da impossibilidade de separar completa e simetricamente os dois blocos. É certo animal no homem e certo homem no animal que é visado, sem identidades definitivamente constituídos. (NASCIMENTO, 2012, p. 30)

Obviamente, como se mostra na crônica, não há aproximação tête-à-tête, dado que seria no olhar do bicho, como se dá em outros contos e romances de Clarice Lispector, a exemplo de "O búfalo" (1960) e A Paixão Segundo G.H. (1964), respectivamente. Entretanto, vemos a potência de um devir se constituir com intensidade nesta crônica. Entendemos, aqui, devir, na maneira como pensaram Deleuze e Guattari (1980), cuja relação homem/animal acontece no plano do real, sem a perda de nenhuma identidade dos envolvidos, momento que estaria por prefigurar a alteridade.

Portanto, neste envolvimento reflexivo do Eu em direção àquelas baleias entregues ao poder dos homens, arrastadas que estão para a morte, a relação se inscreve como pensamento no interior do sujeito da enunciação, como alerta Giorgi (2016), que já tivemos oportunidade de argumentar anteriormente. Instaura-se, pois, em devir. Assim, o animal se coloca, esteticamente, como realidade, em síntese, não são, como assinalam Deleuze e Guattari (1980), "sonhos nem fantasmas" (DELEUZE; GUATTARI, 1980, p. 291, tradução nossa). Ao contrário, é reflexão que nasce no bicho real, sendo os devires, então, 
“perfeitamente reais” (DELEUZE; GUATARRI, 1980, p. 291, tradução nossa). Além disso, se pensarmos que a crônica tem um "laço" muito forte na realidade, embora saibamos da intensidade das crônicas de Clarice, esta questão se evidencia com maior força em "Morte de uma baleia".

Dessa forma, seguindo a leitura de Giorgi (2016), o qual diz ser o animal em Lispector o movimento da interiorização, lugar do doméstico, como se verifica no aparecimento, por exemplo, da barata em A Paixão Segundo G.H., acrescentamos, conforme o argumento de Evando Nascimento (2013) em "Clarice Lispector: les animaux, les choses, la pensée", ser o animal, nesta ficção, a potência que emerge como capacidade e "poder de dizer tudo sobre o humano" (NASCIMENTO, 2013, p. 101, tradução nossa). Ora, temos, aqui, a clave de nossa questão. Pelas baleias, suas agonias, causa de ação antrópica, é possível dizer muito sobre aqueles homens. Com eles, instiga-se uma legitimidade de poder, de matar, de negociar, inclusive, ainda em vida, aqueles viventes. Neste bojo, na crônica, jogase com dois polos: São eles, a vida e a morte. No meio, é o poder que se expande, visto, como parte da crônica, em caráter de reflexão crítica.

Entre as duas direções, a vida e a morte, arrolados no poderio humano (biopolítica), artisticamente, o Eu está imerso. Na crônica, desenvolve-se, entre outras maneiras, pela problematização do silêncio. Este, como constituição do animal, que se realiza apenas em grunhidos, serve de "guia" para se instalar o calar que é possível também no humano, embora de ordens diferentes. Para Maria Esther Maciel (2011) em "Poéticas do animal":

Pensar, imaginar e escrever o animal só pode ser compreendido como uma experiência que se aloja nos limites da linguagem, lá onde a aproximação entre os mundos humano e não humano se torna viável, apesar de eles não compartilharem um registro comum de signos. (MACIEL, 2011, p. 94)

No fundo, a referência ao silêncio em "Morte de uma baleia" coloca-se como oportunidade de problematizar a participação do humano no mundo animal, "visto que os humanos precisam se reconhecer animais para se tornar humanos" (MACIEL, 2011, p. 87). Sendo assim, é por via deste intento que entendemos esta passagem, citada, em parte, 
anteriormente: "quantas vezes num silêncio humano - que é o mais grave de todos do reino animal - quantas vezes num silêncio humano minha alma agonizando esperava por uma morte que não vinha" (LISPECTOR, 1968, p. 2). Desse modo, pela agonia daqueles animais, dados também como cativos do poder humano, o Eu, como se apresenta na crônica, expande um dos planos, aquele da vida e morte, destacando a última, feito, neste viés, para o alargamento de si, em itinerários de interiorização, como sublinha Giorgi (2016) para o caso de G.H, que, pela barata, transcorre o seu puro íntimo. Assim, pela morte, imbricada na do bicho, ela se pensa:

Como se meu corpo precisasse dar ao mundo uma prova contrária de minha morte interna para esta ser mais secreta ainda. Morri de muitas mortes e mantê-las-ei em segredo até que a morte do corpo venha, e alguém, adivinhando, diga: esta, esta viveu.

Porque aquele que mais experimenta o martírio é dele que se poderá dizer: este, sim, este viveu. (LISPECTOR, 1968, p. 2, grifo nosso)

Temos prefigurado, aqui, um movimento que perpassa pela mais radical de todas as alteridades. "Esta", como se apresenta, se emaranha, internamente, nas questões relacionadas à morte, enfatizando-a pelo martírio do corpo. Indagamo-nos, no que tange ao animal, o que isto significa para o Outro, isto é, desta reflexão que fala de si, mas que nasce de um Outro? Acreditamos estar implicado na passagem que grifamos a radicalidade deste colocar-se no lugar do Outro, de um sofrer junto. Dá-se pelo martírio que implica a vida, ou seja, um sofrimento que resgata a verdadeira vivência experimentada em dor. Consideramos, neste caso, um alargamento de uma particularidade sublime, próprio do humano, para o mundo dos bichos, não para este se tornar homem, perdendo sua identidade, mas para fazer-nos pensar o martírio desses demais viventes que estão no mundo, que também carregam, no corpo, experiências.

Para o entendimento do sublime e seu nascedouro no sofrimento, recorremos a Friedrich Schiller (2011) em seu Do sublime ao trágico. Para ele, "um objeto é sublime de modo prático na medida em que traz consigo a representação de um perigo que nossa força física não se sente capaz de vencer” (SCHILLER, 2011, p. 25). Neste ponto, é o temor, o perigo e a dor que "elevam" o sujeito à participar de uma particularidade da sublimidade. 
Não estamos querendo dizer, com isto, que os animais estão para os homens na mesma similaridade moral, haja vista que estes não possuem qualquer construção de uma ética coletiva, ao contrário, do homem que vive sob a égide de moralidades, criação humana, ligadas a um determinado tempo específico. No entanto, o sujeito da enunciação, convida os leitores a pensarem sobre estes corpos, incluindo-se no sofrimento, assim como faz isto por meio de uma afirmação fundante: "Se fosse um homem que estivesse agonizando na praia durante oito horas nós o santificaríamos" (LISPECTOR, 1968, p. 2).

Dessa maneira, ela se indaga e coloca-nos como espectadores deste sofrimento do Outro: Se santificamos a dor do homem, fonte do sublime ao sucumbir pelo sofrimento e pela limitação física, não deveríamos, ao menos, sentir um "horror" diante de uma baleia que é vendida, ainda viva, aos quilos? Aproveitando o comentário sobre o sublime, como entende Schiller (2011), cremos que o homem, nesta história, comporta-se como uma espécie de deus, detentor do poder, que sacrifica e envia ao castigo o Outro, como Zeus, ao enviar o Titã Prometeu ${ }^{7}$ para um monte, para que este tivesse o fígado comido todos os dias por uma ave: "Lembro-me de um amigo que há poucos dias citou o que um dos apóstolos disse de nós: vós sois deuses” (LISPECTOR, 1968, p. 2). Portanto, do mítico à realidade, vemos constituir-se sempre a vontade de poder sobre a vida alheia, com ela, castigase e se amplia o martírio em torturas, que, muitas vezes, "santifica os homens". Fê-los pelo sublime. Todavia, questionamo-nos, existiria um "espaço" na afetividade humana para a comoção em relação à dor animal, como se dá com certos homens, que são torturados, crucificados, enfim, que têm a carne "retalhada"?

Para isto, em síntese, o sujeito da enunciação se "arma” de intenções que deveriam tocar-nos, afetivamente, para, enfim, problematizarmos a questão do limite de poder que exercemos sobre os animais. No fundo, ela pretende inserir-se como partícipe de "martírios", para indagarmos sobre os viventes que experimentam de dores e limitações. Com

${ }^{7}$ Cf. SCHILLER, 2011, p. 39: "Sublime foi Prometeu, porque acorrentado ao Cáucaso não se arrependeu de seu ato. [...] Grandes podemos nos mostrar na felicidade, sublimes apenas na infelicidade." 
isto, resgata-se uma reflexão pelas vias da biopolítica, como fica claro, sobretudo, nas literaturas latino-americanas, no qual já comentamos. Para Giorgi:

A vida animal começará, de modos cada vez mais insistentes, a irromper no interior das casas, das prisões, das cidades; os espaços da política e do político verão emergir em seu interior uma vida animal para a qual não têm nome; sobretudo, ali onde se interrogue o corpo, seus desejos, suas doenças, suas paixões e seus afetos, ali onde o corpo se torne um protagonista e um motor das investigações estéticas e a uma só vez horizonte de apostas políticas, despontará uma animalidade que já não poderá ser separada com precisão da vida bumana. (GIORGI, 2016, p. 8, grifo nosso)

Assim, o animal invade a cultura, manifestando-se como questão política. Como assinala Giorgi, a animalidade entra nas casas, sendo, este, portanto, também o papel de certas crônicas neste momento, como se vê em "Morte de uma baleia", de Clarice Lispector. Nelas, amplia-se uma discussão sobre a vida e a morte dos bichos, problematizandose, para isto, o poder como via de acesso ao direito sobre o corpo alheio. Direito, este, de matar, martirizar, diminuir, domesticar, abandonar, ou, simplesmente, comê-los por curiosidade. É o que se questiona no excerto seguinte:

Enquanto isso as notícias misturadas com lendas corriam pela cidade do Leme. Uns diziam que a baleia do Leblon ainda morrera mas que sua carne retalhada em vida era vendida por quilos pois carne de baleia era ótimo de se comer, e era barato, era isso que corria pela cidade do Leme. E eu pensei: maldito seja aquele que a comerá por curiosidade, só perdoarei quem tem fome, aquela fome antiga dos pobres. (LISPECTOR, 1968, p. 2, grifo nosso)

No trecho, é evidente o lugar daquele animal, o da marginalização, marcada em seu corpo: "e era barata". Poder-se-ia, neste momento, inquirirmos sobre os viventes que são esquecidos e abandonados, que, no entanto, convivem, em certa medida e limite, com outras vidas, as que são cuidadas, que têm um futuro. São mendigos, loucos, pretos favelados, homossexuais, prostitutas, órfãos, velhos esquecidos em asilos, doentes entregues à própria 
sorte em hospitais insalubres e sem estrutura física adequada, enfim, são Macabéas ${ }^{8}$. Provase, com este intento, que o poder sobre a vida não se limita apenas aos animais, expandindose, com grande peso, a certos homens marginais, que estão a viver sempre na margem, encalhados, e, quando muito, metaforicamente, "retalhados" em vida, no fundo, aqueles que são facilmente arrastados para a morte, sem comoção e horror dos "donos do futuro". Ela, aquela que foi capaz de sentir "horror" diante das notícias que lhe chegavam, continua:

Outros, no limiar do horror, contavam que também a baleia do Leme, embora ainda viva e arfante, tinha seus quilos cortados para serem vendidos. Como acreditar que não se espera nem a morte para um ser comer outro ser? Não quero acreditar que alguém desrespeite tanto a vida e a morte, nossa criação humana, e que coma vorazmente, só por ser uma iguaria, aquilo que ainda agoniza, só porque é mais barato, só porque na verdade somos tão ferozes como um animal, só porque queremos comer daquela montanha de inocência que é uma baleia, assim como comemos a inocência de um pássaro. Eu ia dizer agora com horror: a viver desse modo, prefiro a morte. (LISPECTOR, 1968, p. 2)

Neste sentido, como temos abordado até o presente momento, a ficção de Clarice, mesmo nas crônicas, elabora-se como oportunidade de pensar o mundo, as relações, a vida e a morte, implicadas na política e no poder. Trata-se, conforme Nascimento (2012), da capacidade pensante desta literatura. Assim, este Eu que se horroriza em "Morte de uma baleia", amplia uma discussão em torno de uma "montanha de inocência", a baleia, a qual carrega em seu escopo, a imagem de todos aqueles, que, socialmente, são excluídos e levados ao perigo e à morte, muitas vezes, sob a tortura. A crônica, corpus de nosso estudo, então, amplia-se em reflexão, inserindo o animal como signo político, posto como motivo para pensar a si mesmo, o humano, em geral, assim como as práticas de poder sobre a vida alheia. Dessa forma, a narrativa clariceana, esta veiculada no Jornal do Brasil, em 1968, e, que

${ }^{8}$ Cf. SÁ, 2017, p. 140: "Vivendo na grande cidade do Rio de Janeiro, num quarto alugado, com quatro balconistas das Lojas Americanas, não longe do cais do porto, lugar de marinheiros e prostitutas, Macabéa pertence, socialmente falando, à classe dos marginalizados. E denuncia: a marginalização da mulher, de muitas espécies de mulheres: as feias, as incompetentes, mal cheirosas, órfãs de pai e mãe, encardidas, raquíticas, tuberculosas, aidéticas, mal amadas, sonhadoras, esfomeadas, balconistas, solteironas, prostitutas, manchadas de 'panos', as velhas, donas de casa, neuróticas." 
pode alargar-se, naturalmente, para várias de suas escrituras, estimula-nos a pensar, politicamente, as vidas, sobretudo, tornando "o animal um foco de intensidades a uma só vez estéticas e políticas" (GIORGI, 2016, p. 49). Por meio dele, quem sabe, resgata-se a possibilidade de uma verdadeira humanidade.

E exatamente não é verdade. Sou uma feroz entre os ferozes seres humanos - nós, os macacos de nós mesmos, nós, os macacos que idealizaram tornaram-se homens, e esta é também a nossa grandeza. Nunca atingiremos em nós o ser humano: a busca e o esforço serão permanentes. E quem atinge o quase impossível estágio de Ser Humano, é justo que seja santificado. (LISPECTOR, 1989, p. 2)

Acreditamos, pois, que por meio do animal, talvez, pela morte de uma baleia inocente, seja possível resgatar um verdadeiro humano, esta que é também a "nossa grandeza", isto é, tenta-se "revalidar" ou "reativar" este esforço "permanente" de sermos atingidos, afetivamente, com a dor destes vários corpos marginais. Em síntese, o animal como signo político na crônica, revela-se fomentador de questões mais amplas, como "as vidas por proteger e as vidas por explorar; entre as vidas propriamente humanas e as vidas por subordinar, por explorar, por coisificar, e por eliminar- as vidas que se vendem e se compram nos mercados globais ou as vidas elimináveis na nova ordem política” (GIORGI, 2016, p. $70)$.

Inferimos na crônica, além disso, um Eu, a mulher horrorizada, que, pela linguagem, talvez, esteja falando pelo animal. Por meio dela, sabemos sobre aquela dor e agonia, sensações misturadas pela venda de parte do corpo, em preço barato para servir em iguarias, por sua vez, de valor irrisório. Em resumo, é quase um “ouvir” aquele bicho, sua experiência de martírio, que poderia dizer o que são alguns humanos, o que eles representam para muitos viventes: donos do futuro, ou não, de outros, em síntese, aqueles que têm o poder de decidir pela vida ou pela morte de uma "montanha de inocência".

"Em Poéticas do animal”, Maria Esther Maciel (2011) afirma o intento de alguns artistas em dizer pelo animal: "Nesse contexto é o esforço de vários poetas em apreender, pela palavra articulada, o 'eu' dos animais não humanos, entrar na pele deles, imaginar o que eles diriam se tivessem o domínio da linguagem humana" (MACIEL, 2011, p. 95). 
Perguntamo-nos, com este argumento de Maciel sobre o "animal como sujeito", o que diria aquela baleia aos seus algozes, para aqueles que não esperaram a sua morte para vendê-la, distribuí-la aos compradores, desejosos que são de carne barata? Pensando nisto, na passagem seguinte, é possível inferirmos um duplo sentido por meio do verbo "dizer": "Não fui ver a baleia que estava a bem dizer à porta de minha casa a morrer. Morte, eu te odeio" (LISPECTOR, 1968, p. 2, grifo nosso).

Assim, seguimos nosso questionamento. Ela, a baleia, perdoaria, como o sujeito da enunciação, apenas os pobres? São perguntas difíceis de responder, porque envolve uma particularidade política e social, segundo a qual a carne do bicho não deveria servir para saciar desejos, antes, deveria estar implicada apenas no matar a fome, talvez, de pobres. Mas, indagamo-nos, justifica-se a retirada da carne do animal ainda vivo, em plena latência? No fundo, sabemos, se aquela baleia possuísse a capacidade da linguagem humana, confirmaria a animalidade voraz daqueles vendedores de "carne viva", ou ainda, ratificaria "os macacos que somos", longe que estamos de Ser Humanos, porque, "desistir de nossa animalidade é um sacrifício" (LISPECTOR, 1968, p. 2). Neste viés, sabemos da dificuldade de muitos em deixar de comer a carne animal, do não humano, entretanto, por que naturalizamos a dor daqueles que comemos? Além disso, num suposto cenário político, é possível falar em "morte digna"? São algumas questões que "Morte de uma baleia" nos coloca. Vale ressaltar que o poder sobre a vida e a morte são problematizações presentes em muitas sociedades, como alerta Giorgi (2016):

Não há sociedade nem, provavelmente, subjetividades que não tenham de enfrentar em algum momento essa decisão sobre o viver $\mathrm{e}$ o morrer, próprio ou alheio: desde as decisões em torno do nascimento e da reprodução até a "morte digna", em escala individual e familiar. [...] as condições e dispositivos de proteção e abandono permeiam e definem em grande medida a vida dos sujeitos e das sociedades; ali a relação política ou politizável, sempre móvel, incerta, com essas vidas cuja morte não constitui delito traça um vetor crucial do político e do ético. (GIORGI, 2016, p. 23)

Decorridas algumas décadas da publicação de "Morte de uma baleia", quase no final da década de 1960, interrogamo-nos: como lidamos, hoje, com o sofrimento de animais, 
violentados, muitas vezes, com choque elétrico no caminho ao matadouro, espaço de agitação, berros e açoites, na justificativa de se "apurar" as suas carnes, antes da morte? Nós, que vemos a carne cortada e arrumada nos frigoríficos do supermercado, o que diríamos se presenciássemos o tortuoso caminho do bicho em direção ao abate? Desse modo, continuamos a aceitar a dor de certos viventes no desejo de comer uma carne mais "saborosa", de preferência, com baixo custo? Enfim, nesta crônica, vemos emergir uma relação entre um Eu e o animal, mesmo longe, tem-se uma espécie de "enlaces entre corpos e entre materialidades" (GIORGI, 2016, p. 136), como se, nos corpos, da mulher e da baleia, víssemos uma compreensão se dando.

Portanto, o animal como signo político em "Morte de uma baleia", dá-se em um "bios que é relação e não essência: no centro dessa reflexão- em seu ponto de partida, que é também o de sua potência e sua realidade-está o animal, sua proximidade incomensurável, sua promessa de justiça que é sua linha de fuga incessante” (GIORGI, 2016, p. 138-139). Finalizamos dizendo, neste sentido, que a relação Eu/animal, aqui, não se perfaz como questão que se "revela", como seria numa perspectiva ontológica", interessada em "verdades originárias" e por "totalidades", herança de uma compreensão humanista do Mundo e do Ser, que privilegia apenas o homem. Em nossa leitura de "Morte de uma baleia", ao contrário, encaminha-se num “enlace”, numa contribuição mútua e material, marcada nos corpos, no bios, do humano e do não-humano.

\section{Considerações finais}

Em nosso estudo, desenvolvemos uma reflexão crítica a respeito do poder sobre a vida e a morte, base da biopolítica, em "Morte de uma baleia", de Clarice Lispector, crônica publicada pela primeira vez no Jornal do Brasil, em 17 de agosto de 1968. Nosso intento,

${ }^{9}$ Cf. GIORGI, 2016, p. 210-211: "Muitas inscrições do animal na cultura das últimas décadas funcionam como signos políticos que disputam não tanto a noção do 'humano' como ontologia e como hierarquia sobre o restante do vivente - isto é: em termos de uma discussão crítica da tradição humanista - como às distinções políticas entre 'vidas' - entre as vidas que se protegem e se reconhecem socialmente, e as vidas marcadas para a exploração, o consumo ou a precariedade, a distinção, enfim, entre as 'pessoas' (em princípios 'humanas') e as vidas não pessoais" 
neste trabalho, foi demarcar a questão que coloca o animal como parte de uma discussão mais ampla, tendo-o como "signo político", porque, no plano artístico, por meio dele, instiga-se toda uma proposta que envolve uma ética e uma política, enfim, decisões sobre vidas que devem ser cuidadas, protegidas, em contraposição, a outras, sempre marginalizadas, levadas, facilmente, para a morte, pois pertencem aos seres de "carne barata".

Por fim, como Macabéa, os animais encalhados na praia, participam, temporalmente, de um grupo de viventes marginalizados. Na crônica, ressaltamos um acontecimento que se arrola na clave do poder sobre aquela "montanha de inocência". São os viventes mortos, trocados, negociados, abandonados e vendidos por quantia irrelevante no mercado local e global. No fundo, ela representa aquelas carnes de pouco valor e sem direito ao futuro. No texto, identificamos um Eu que se vê no animal; em síntese, que é capaz de sentir horror diante da morte e da negociação da "carne viva" dos inocentes.

\title{
“MORTE DE UMA BALEIA", BY CLARICE LISPECTOR: FOR A BIOPOLITICS WRITING
}

\begin{abstract}
The present study aims critically to reflect "Morte de uma baleia" chronicle, by Clarice Lispector (1920-1977), published for the first time in Jornal do Brasil, on August 17, 1968. For this, we will develop an analysis by the biopolitics perspective, in which it helps us to think, in the artistic plane, the animality as a question that establishes a political discussion, especially around the relationship between life, death and power. In this article, we highlight the studies by Giorgi (2016), Nascimento (2012, 2013) and Maciel (2011). Beside these last, we also emphasize the reflections about the animal and the becoming in Deleuze and Guatarri (1980).
\end{abstract}

KEYWORDS: Clarice Lispector, "Morte de uma baleia", Biopolitics.

\section{REFERÊNCIAS}

DELEUZE, Gilles; GUATTARI, Félix. Mille Plateaux: Capitalisme et Schizophrénie. Paris: Les Éditions de Minuit, 1980. 641 p.

GIORGI, Gabriel. Formas Comuns: animalidade, literatura, biopolitica. Trad. Carlos Nougué. Rio de Janeiro: Rocco, 2016. 238 p.

LISPECTOR, Clarice. Morte de uma baleia. Jornal do Brasil, Rio de Janeiro, n. 111, p. 2, 17 ago., 1968. 
MACIEL, Maria Esther. Poéticas do animal. In: MACIEL, Maria Esther (Org.) Pensar/ escrever o animal: ensaios de zoopoética e biopolitica. Florianópolis: Ed. UFSC, 2011, p. 85-101.

MOISÉS, Massaud. Crônica. In: Dicionário de Termos Literários. São Paulo: Cultrix, 2013, p. 112-113.

NASCIMENTO, Evando. Clarice Lispector: les animaux, les choses, la pensée. In: BESSE, Maria Graciete; SETTI, Nadia (Org.). Clarice Lispector: une pensée en écriture pour notre temps. Paris: L'Harmattan, 2013, p. 99-117.

NASCIMENTO, Evando. Clarice Lispector: uma literatura pensante. Rio de Janeiro: Civilização Brasileira, 2012. 303 p.

ROSENBAUM, Yudith. Entre a loucura e a lucidez: crônicas de Clarice Lispector no Jornal do Brasil. Journal of Lusophone Studies, Stanford, v.4, n. 2, p. 75-96, 2019.

SÁ, Olga de. Lamento de um blue. Fólio-Revista de Letras, Vitória da Conquista, v.9, n.2, p. 135-151, jul.-dez., 2017.

SCHILLER, Friedrich. Do Sublime ao trágico. Trad. Pedro Süssekind e Vladimir Vieira.

Belo Horizonte: Autêntica, 2011. 123 p.

Recebido em: 13/07/2020.

Aprovado em: 15/10/2020. 


\section{Anexo}

PAGINA 2 JORNAL DO BRASI RIO DE JANEIRO II SABADO, 17 DE AGOSTO DE 1968

\section{Clarice Lispector}

MORTE DE: UMA BALEIA

Em minutos espalhara-se. noticia: uma baleia no leme o ou
tir no Leblon haviam surgido arrebentacio de onde tinham tontado wir 100 no entanto po apesar do upenas filhotes. Todos foram ver, Eu njo fuit corria. boato de que ela agonizava is hid oito horas e que atb atirat ne nuava agonizando mas ela conti.

Senti um horror diante do que connisum ho que diver nì mas a lenda is estavs formads en tórno do extraordinbrio que enfium, enfiml scontecis, pois per mos sempre a etpera do extraor. dinbrio que talvex nos salve de ums vida contida. So fosce ven na praia durante sito horas nós. sentificariamos, tanto precisamos de crer no que é impossivel.

Nào, nỏo fui vá-ls: detesto. morte. Deus, o que nos prometeis inferno cada um do nós em regrido que. do propris apocalipse. E ? pro pria mert

Fora dax vézes em que quase
morri parz sempre, quantas ve. res num siltencio humano - que

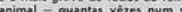
lencio humano minha alma ago nizando esperava por uma mo nio por a rib en que minha alma sangrats. era quando o corpo mais floce. ca dar o mundo ump prova traris de minha morte interna pa Zi. esth ser mais secrets ainda. Morri de muitas mortes o man morte do corpo venha, o alguém, vev. Porque aquelle que mais ex.
perimenta o martirio d dtlo que
se poderi dizeri áste, sim, este pordera

O mais estrantio é que tôdas at vires em que era so. corpo que estava d morte, a slma o der meu corpo quase morreu, igno. especio de rars alegris como quento o corpo dois como ferno. Uma das vases, to depois que passou a que me disseram vida e morte. e nada garantiam os medicos, senào que tudo ter. tariam. E eu taso inocente do que va nbo permitirem visitas. Mas ou quere visitas, dizia, elas me distraem da dor terrivel. E todos os que najo obodeceram a place por mim, gemendo de dor, como tolante of minhs vox era clars: $m$ nhe alma florescia como um b. realmente muito zangado e num tom definitivo disse-mo: ma extado mesmo en que vocé o. to. "O estedo em que ev estava" eu a desconhocis, nunce nesses morte. Parece-me que eu vaga mente sentia que, enquanto 10 tío insuportivel, isso seria a pro Lex que so other ugora do ums vex que so othar um por de se ou agonizei com ele lentamente cobrindo-me de mistria de por eansaso, suevmbindo num sono que completavs a minh morte. E qusndo reordei, sur meiros infimos instantes do scor is morta se converva. consciat cas? Alt que o corpo habituado. moverse eutomaticamente me de passar a máo pelos cabelon. Entiso num susto percebi que mou corpo. minhe alma tinham ta de estar morts. a descobert do que uu estavs viva - tudo is dois infimos regundos ou talver em diante todos nibum stray de mim que náo estou mentindo emir menor de dors regundos $p$ te e ums vida de nôvo frues dois infimos segunder como forma do contar toseamente o tempa. dove no. O animal asim como Deus alvex conte o rempo en frasbee de século dos seculos: cads si. cullo um instante. Quem sabe se
Devis conts a noss vids em tor. mos de dois segundos: um para nascer o outro para moerer. E: maior criasão do Homems av vida. uma vida. Lembro-me de Um amigo que his pouces diass citou äs: vós sois devses.

Sim, jure que somos devies. Porque eu tamberm ib morri de vida. E quando passava etsa en pecie de glorioss o suave morte, eu me surpreendia de que : dor, de que houverse uma disci. plins pars cads coirs, e de que eu mesma, a comesar por mim, to. coting penura que rempo ti. nhe paredo e os homens subits. mente se tinham imobilizado no maio do gesto que estivessem ri. mone por alegris.

Nbo fui ver a baleis que es. tava a bem dizer bo ports de mi. odeie.

Enquanto liso as noticias misturadas com lendas corrism tiam que a baleia do Leblon ain. a retalhado mas que sus car. de por quiles poin carne de ba. leis erra brimo de se comer, e oen maldito seja squelle que o. come. rápor curiosidade, sob perdoarei quem lem forve.

Outros, no limiar do horror. contavam que iamberm a baleia fante, tinhe sovis quiles cortados pers serem vendides. Como acre. ditar que nato se espera nem a ser? Nao quero screditar que atguém desrespeite tanto a vida. : morte, nosso criacajo humana, uma iguatis, aquilo que sor ser agoniza, it porque of mais barato, as porque a fome humans. gramde, io porque no verdade. mul faroz, s6 porque queremos comer daquels montanhe do ino como comemos a inoctncis can tante de um pissaro. Ev is dizee agora com horror: A viver desse de. Sou unatamente najo 6 verde. res seres humanos - nobs, or ma. macaces que idealizaram torne rem-se homens, o esta 6 tambàm noss grandese. Nunca ating. burcs 0.0 esfóres serio perma. nentes. I quem atinge o quase no. $\dot{b}$ ivato Porque desingir de nosss ani.

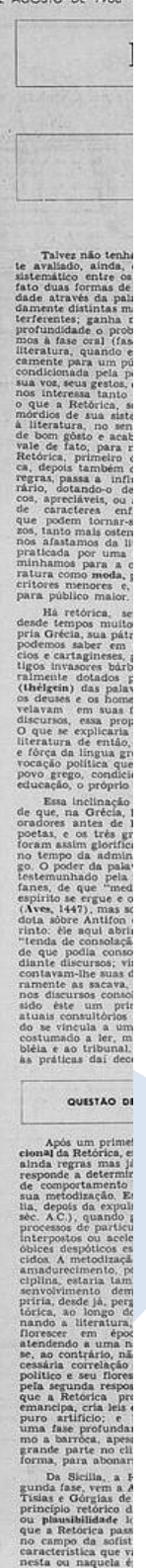

no campo da softisi
caracteristica que
nesta 